PREPARED FOR THE U.S. DEPARTMENT OF ENERGY, UNDER CONTRACT DE-AC02-76CH03073

PPPL-3816

PPPL-3816

UC-70

High-harmonic Fast Wave Driven H-mode

Plasmas on NSTX

by

B.P. LeBlanc, R.E. Bell, S.I. Bernabei, K. Indireshkumar, S.M. Kaye,

R. Maingi, T.K. Mau, D.W. Swain, G. Taylor, P.M. Ryan,

J.B. Wilgen and J.R. Wilson

May 2003

$\left.\stackrel{M}{M}\right|_{\substack{\text { PRInCETON PLASIMA } \\ \text { PHYSICS LABORATORY }}} ^{D}$

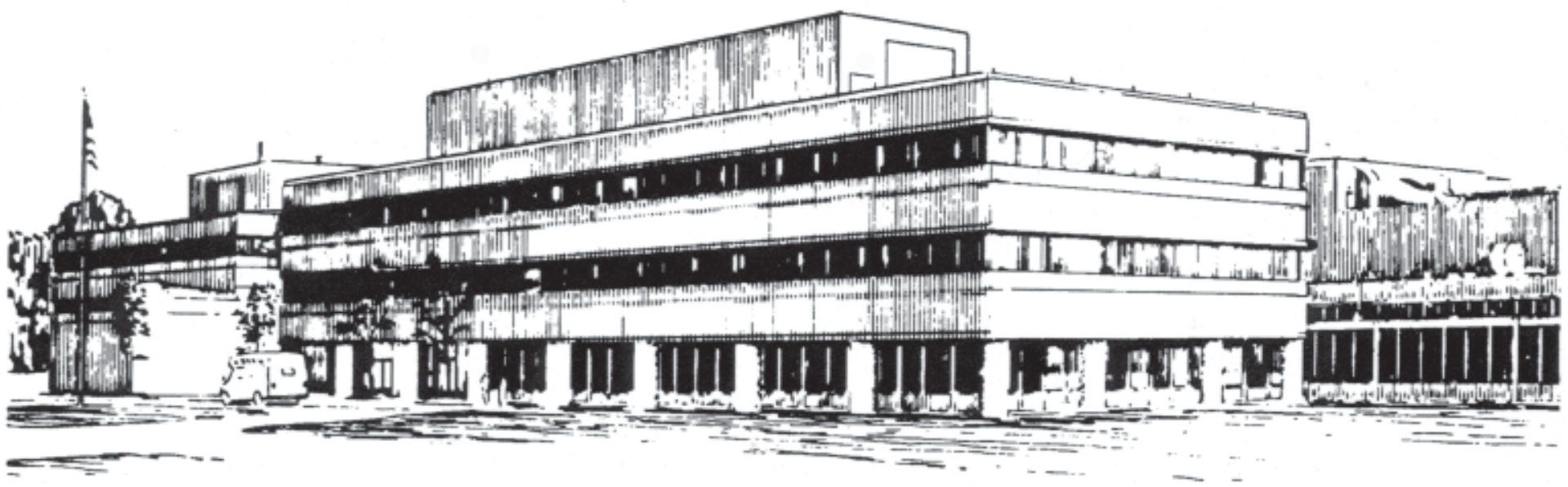

PRINCETON PLASMA PHYSICS LABORATORY PRINCETON UNIVERSITY, PRINCETON, NEW JERSEY 


\section{PPPL Reports Disclaimer}

This report was prepared as an account of work sponsored by an agency of the United States Government. Neither the United States Government nor any agency thereof, nor any of their employees, makes any warranty, express or implied, or assumes any legal liability or responsibility for the accuracy, completeness, or usefulness of any information, apparatus, product, or process disclosed, or represents that its use would not infringe privately owned rights. Reference herein to any specific commercial product, process, or service by trade name, trademark, manufacturer, or otherwise, does not necessarily constitute or imply its endorsement, recommendation, or favoring by the United States Government or any agency thereof. The views and opinions of authors expressed herein do not necessarily state or reflect those of the United States Government or any agency thereof.

\section{Availability}

This report is posted on the U.S. Department of Energy's Princeton Plasma Physics Laboratory Publications and Reports web site in Fiscal Year 2003. The home page for PPPL Reports and Publications is: http://www.pppl.gov/pub_report/

DOE and DOE Contractors can obtain copies of this report from:

U.S. Department of Energy

Office of Scientific and Technical Information

DOE Technical Information Services (DTIS)

P.O. Box 62

Oak Ridge, TN 37831

Telephone: (865) 576-8401

Fax: (865) 576-5728

Email: reports@adonis.osti.gov

This report is available to the general public from:

National Technical Information Service

U.S. Department of Commerce

5285 Port Royal Road

Springfield, VA 22161

Telephone: $1-800-553-6847$ or

(703) $605-6000$

Fax: (703) 321-8547

Internet: http://www.ntis.gov/ordering.htm 


\title{
High-Harmonic Fast Wave Driven H-mode Plasmas on NSTX*
}

\author{
B.P. LeBlanc ${ }^{\mathrm{a}}$, R.E. Bell ${ }^{\mathrm{a}}$, S.I. Bernabei ${ }^{\mathrm{a}}$, K. Indireshkumar ${ }^{\mathrm{a}}$, S.M. Kaye ${ }^{\mathrm{a}}$, \\ R. Maingi ${ }^{b}$, T.K. Mau', D. W. Swain ${ }^{b}$, G. Taylor ${ }^{a}$, P. M. Ryan ${ }^{b}$, \\ J.B Wilgen ${ }^{\mathrm{b}}$, J.R. Wilson ${ }^{\mathrm{a}}$ \\ ${ }^{a}$ Princeton Plasma Physics Laboratory, Princeton, New Jersey 08543 \\ ${ }^{b}$ Oak Ridge national Laboratory, Oak Ridge, Tennessee 37830 \\ ${ }^{c}$ UCSD, San Diego, California
}

\begin{abstract}
The launch of High-Harmonic Fast Waves (HHFW) routinely provides auxiliary power to NSTX plasmas, where it is used to heat electrons and pursue drive current. H-mode transitions have been observed in deuterium discharges, where only HHFW and ohmic heating, and no neutral beam injection (NBI), were applied to the plasma. The usual H-mode signatures are observed. A drop of the D $\alpha$ light marks the start of a stored energy increase, which can double the energy content. These H-mode plasmas also have the expected kinetic profile signatures with steep edge density and electron temperature pedestal. Similar to its NBI driven counterpart - also observed on NSTX - the HHFW H mode have density profiles that features "ears" in the peripheral region. These plasmas are likely candidates for long pulse operation because of the combination of bootstrap current, associated with H-mode kinetic profiles, and active current drive, which can be generated with HHFW power.
\end{abstract}

\section{INTRODUCTION}

The application of High Harmonic Fast Wave (HHFW) constitutes an important element of the NSTX research program, where it is used to heat bulk electrons and pursue non-inductive drive current $[1,2]$. Substantial progress has been achieved over the results presented at the previous meeting of this conference [3], and effective heating has been achieved in helium and deuterium plasmas for different antenna $k / /$. In particular electron temperature, $T_{e}$, up to $3.9 \mathrm{keV}$ has been measured, with profile behavior suggestive of a thermal electron internal transport barrier [4]. NSTX operates naturally at high beta, with parameters entailing wave physics with dielectric constant $\varepsilon \equiv \omega_{p e}{ }^{2} / \Omega_{\varepsilon}{ }^{2} \approx 50-100$, which is large compared to conventional tokamak, where $\varepsilon \approx 1$. For such high $\varepsilon$-value plasmas, an attractive fast-wave window opens in the high harmonic frequency range, $\Omega_{i}<<\omega<<\omega_{L H}$, which permits electron heating and current drive [5]. A welcome result has been the observation of H-mode transition during HHFW heating. Such transitions are readily observed when HHFW provides the sole source of auxiliary heating. So far all the H-mode transitions have been observed with lower single null configuration (LSN) and at plasma current lower or equal to 0.5 MA. Attempts made at higher current were not successful, but a systematic study has not been performed to date. In this paper we review some of the parameters of these 
plasmas and make use of a recent implementation of the ray tracing code CURRAY [6] into the data regression code TRANSP [7] to study the time dependent power deposition under HHFW driven H-mode conditions.

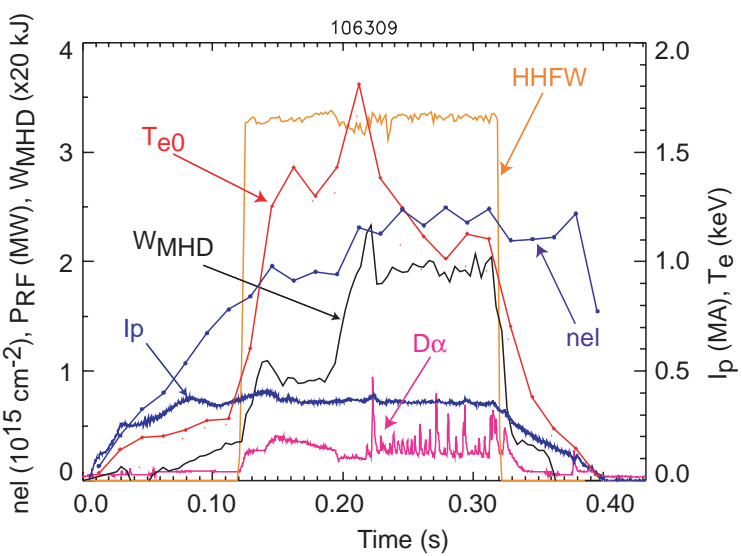

Figure 1. Time evolution of an HHFW driven Hmode discharge. The transition is seen at $0.195 \mathrm{~s}$ on the $\mathrm{D}_{-}$trace; stored energy WMHD doubles. A drop in Te0 occurs during the ELM activity.

\section{HHFW DRIVEN H-MODE PLASMAS}

The relevant parameters for a HHFW driven H-mode discharge in deuterium are shown in Fig.1. The plasma current is $0.36 \mathrm{MA}$, and the magnetic field is $0.45 \mathrm{~T}$. HHFW power of $3.3 \mathrm{MW}$ is applied during interval $0.12-0.32 \mathrm{~s}$. The HHFW frequency is $30 \mathrm{MHz}$ with $k_{/ /}=14 \mathrm{~m}^{-1} . T_{e 0}$ rapidly responds to the HHFW power by increasing from $0.3 \mathrm{keV}$ to nearly 1.5 $\mathrm{keV}$ in $0.05 \mathrm{~s}$. The $\mathrm{H}$ transition occurred at $0.195 \mathrm{~s}$ and was accompanied by further heating of the electrons and a doubling in the stored energy. The decrease in central electron temperature observed later on could have resulted from power-coupling losses caused by MHD activity or the ELMs (visible on the $\mathrm{D}_{\alpha}$ trace). TRANSP analysis predicts a $40 \%$ bootstrap current fraction for this discharge.

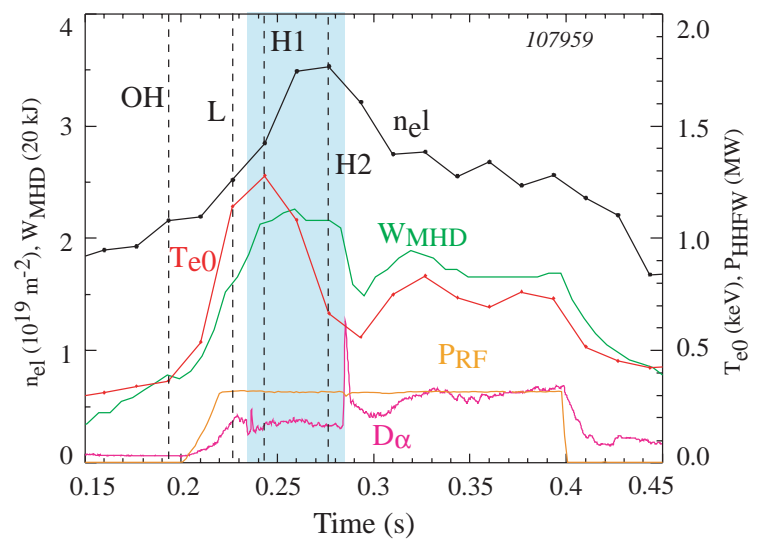

\section{Kinetic Documentation}

We can see in Fig. 2 a temporal overlay of plasma parameters for a deuterium discharge with plasma current of 0.5 MA and toroidal field of $0.45 \mathrm{~T}$. The HHFW power $3.2 \mathrm{MW}$ pulse is applied from 0.2 to $0.4 \mathrm{~s}$ and is the sole source of auxiliary power. The antenna $\mathrm{k} / /$ is $14 \mathrm{~m}^{-1}$ and the frequency $30 \mathrm{MHz}$. As a result of the

Figure 2. Time evolution of $\mathrm{HHFW}$ driven $\mathrm{H}$ mode discharge. Time markers $\mathrm{OH}, \mathrm{L}, \mathrm{H} 1$ and $\mathrm{H} 2$ shown with dotted lines.
HHFW heating, the central electron temperature $T_{e 0}$ increases from $\approx 0.4 \mathrm{keV}$ to $\approx 1.1 \mathrm{keV}$, before the onset of the $\mathrm{H}$ phase occurring during the interval 0.235 $0.285 \mathrm{~s}$ as can be seen on the $\mathrm{D}_{\alpha}$ trace. Four time points indicated with vertical dotted lines $-0.193,0.227,0.243,0.277 \mathrm{~s}$ - correspond respectively to the ohmic phase 
$(\mathrm{OH})$, the L phase (L), the early and late $\mathrm{H}$ phase $(\mathrm{H} 1$ and $\mathrm{H} 2)$. Also seen in the figure are the line-integrated density, $n_{e} l$, and the magnetically derived stored energy, $W_{M H D}$.
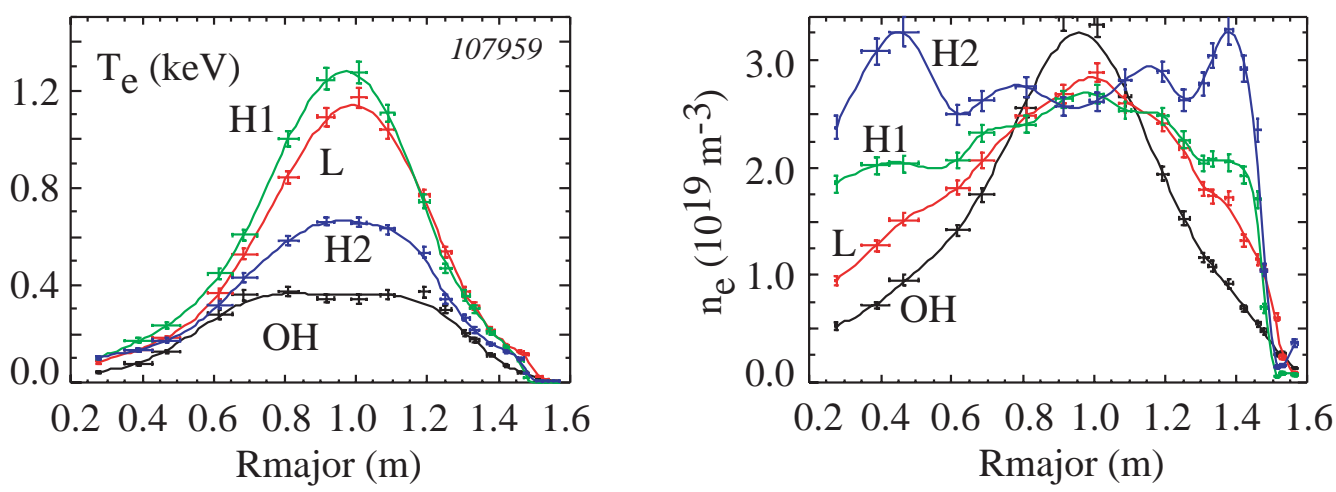

Figure 3. Temporal overlays of $T_{e}(R)$, and $n_{e}(R)$ for a HHFW driven H-mode discharge. Four times are shown: ohmic $(\mathrm{OH})$, L-mode $(\mathrm{L})$, early H-mode $(\mathrm{H} 1)$, late H-mode $(\mathrm{H} 2)$.

Kinetic profiles of HHFW driven H-mode plasmas show the expected signatures of this high confinement regime. In Fig. 3, we show $T_{e}(R)$ and $n_{e}(R)$ profiles for the time points marked $\mathrm{OH}, \mathrm{L}, \mathrm{H} 1$ and $\mathrm{H} 2$ in Fig. 2. During the ohmic phase, the $T_{e}$ profile is flat and limited to $0.3 \mathrm{keV}$; the density profile is peaked. During the L phase, we observe a $T_{e}$ increase over the whole profile with the center reaching $1.1 \mathrm{keV}$; the density profile changes from peaked to triangular shape. There is a hint of a edge profile steepening visible on $T_{e}(R)$ and $n_{e}(R)$ outboard data. The early H-mode $n_{e}(R)$

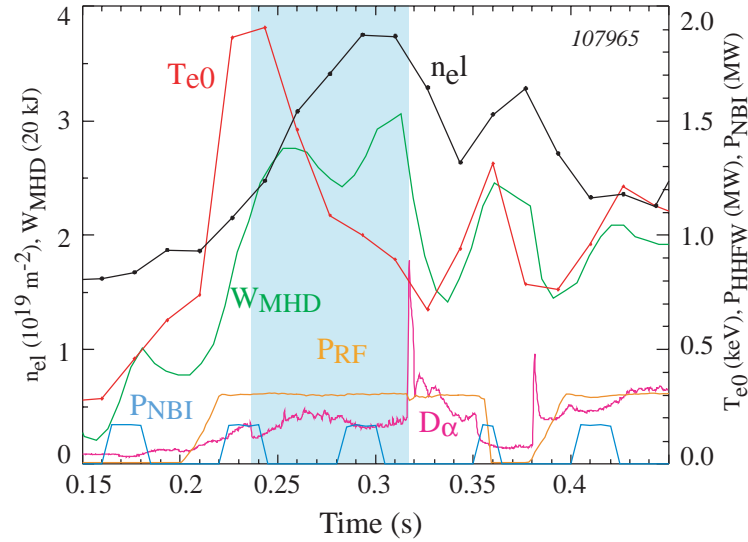

Figure 4. Time evolution of HHFW driven $\mathrm{H}$ mode discharge. Short NBI pulses added for $T_{i}$ measurements data show a well established edge gradient. The plasma column has shifted inwards by $\approx 3 \mathrm{~cm}$ and the electron temperature is slightly increased. The temperature edge pedestal is $\approx 0.12 \mathrm{keV}$. During the later $\mathrm{H}$-mode phase, we observe a fully developed edge density gradient with "ears" near the peripheral regions. Meanwhile the central electron temperature has fallen to $0.6 \mathrm{keV}$.

The discharge shown in Fig. 4 has the same nominal parameters as the one just discussed above, but short neutral beam pulses lasting $0.02 \mathrm{~s}$ were applied from $0.16 \mathrm{~s}$ on to measure the ion temperature profile $T_{i}(R)$ by charge exchange recombination spectroscopy at 0.06 second intervals. As in the above case, the HHFW power is 3.2 MW. Each beam pulse has a power of $1.7 \mathrm{MW}$, but TRANSP calculations indicate that only a power level $\approx$ $0.6 \mathrm{MW}$ contributes to plasma heating. We can see in Fig. 5 plots of the $T_{i}$ and $T_{e}$ and $n_{e}$ profiles during the $\mathrm{L}$ and $\mathrm{H}$ phases at respectively $\approx 0.230 \mathrm{~s}$ and $0.290 \mathrm{~s}$. 


\section{Time Dependent Power Deposition with CURRAY}

The ray tracing code CURRAY has recently been incorporated into the TRANSP code and we can see in Fig. 6 some preliminary analysis results. In panel (a) we see the predicted power absorbed by the electrons. Besides the total power, we also show the power absorbed in the inner region and in the outer region. One can see that during the $\mathrm{H}$ phase, indicated by dotted lines, more power is absorbed in the outer region as a result of the higher peripheral electron density. There are over 150 time points during the HHFW pulse, which gives true temporal information on the power deposition. For example, the drops in the absorbed power occurring, when neutral-beam pulses are present, are caused by wave absorption by fast particles [8]. Panel (b) show the power
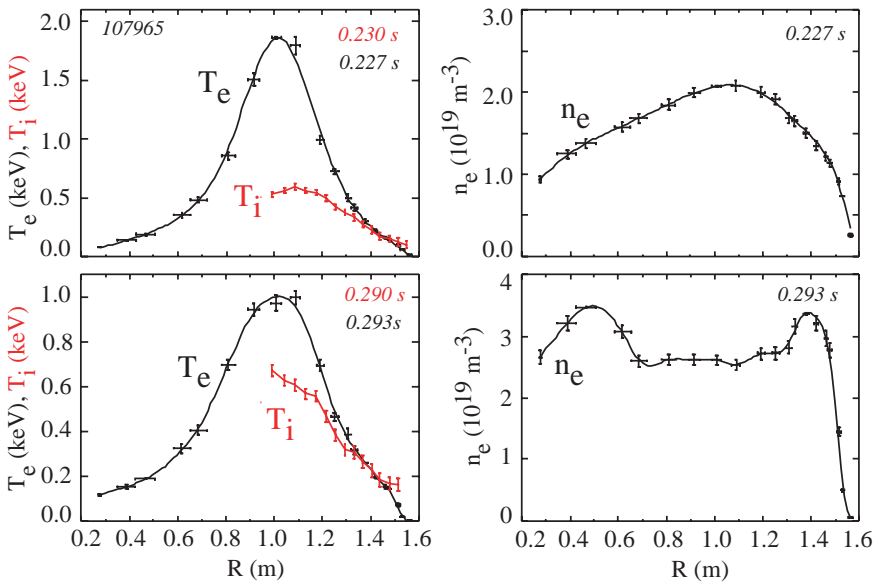

Figure 5. Kinetic profile data at two times near $0.230 \mathrm{~s}$ and $0.290 \mathrm{~s} . T_{i}$ from charge exchange recombination spectroscopy. $T_{e}$ and $n_{e}$ from Thomson scattering.
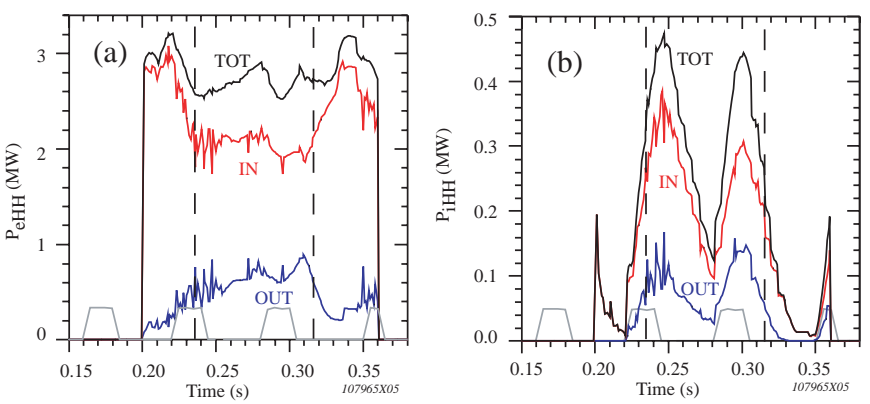

Figure 6. Time evolution of power absorption: (a) power to the electrons; (b) power to the ions. Dotted lines delineate $\mathrm{H}$ phase. Neutral beam blips shown for reference.

absorbed by the ions. Absorption by the fast particle constitutes the dominant term and one can see the ion heating staying in sync with the neutral beam pulses. The quick rise in ion heating at the onset of the HHFW pulse $-0.2 \mathrm{~s}-$ comes from the residual fast ions generated by the beam blip at $0.16 \mathrm{~s}$.

*This work is supported by U.S. DOE contract DE-AC02-76CH03073.

\section{REFERENCES}

1 Wilson, J.R. et al., Phys. Plasmas, Vol. 10, No. 5, (2003) 1733-1738

2 Ryan, P.M, et al. this conference

3 LeBlanc, B.P. et al., R. F. Power in Plasmas, 14 ${ }^{\text {th }}$ Topical meeting, AIP proc. 595, (2001) p 51

4 LeBlanc, B.P. et al. Submitted to Nuclear Fusion

5 Ono ,M., Phys. Plasmas 2 (1995) 4075

6 Mau, T.K.,el., R. F. Power in Plasmas, $14^{\text {th }}$ Topical meeting, AIP proc. 595, (2001) p.170

7 Ongena J., Evrard M., McCune D., "Numerical Transport Codes", in the Proceedings of the Third

Carolus Magnus Summer School on Plasma Physics, (Spa, Belgium, Sept 1997), as published in

Transactions of Fusion Technology, March, 1998, Vol. 33, No. 2T, pp. 181-191.

8 Rosenberg, A et al., this conference. 


\section{External Distribution}

Plasma Research Laboratory, Australian National University, Australia

Professor I.R. Jones, Flinders University, Australia

Professor João Canalle, Instituto de Fisica DEQ/IF - UERJ, Brazil

Mr. Gerson O. Ludwig, Instituto Nacional de Pesquisas, Brazil

Dr. P.H. Sakanaka, Instituto Fisica, Brazil

The Librarian, Culham Laboratory, England

Mrs. S.A. Hutchinson, JET Library, England

Professor M.N. Bussac, Ecole Polytechnique, France

Librarian, Max-Planck-Institut für Plasmaphysik, Germany

Jolan Moldvai, Reports Library, MTA KFKI-ATKI, Hungary

Dr. P. Kaw, Institute for Plasma Research, India

Ms. P.J. Pathak, Librarian, Insitute for Plasma Research, India

Ms. Clelia De Palo, Associazione EURATOM-ENEA, Italy

Dr. G. Grosso, Instituto di Fisica del Plasma, Italy

Librarian, Naka Fusion Research Establishment, JAERI, Japan

Library, Plasma Physics Laboratory, Kyoto University, Japan

Research Information Center, National Institute for Fusion Science, Japan

Dr. O. Mitarai, Kyushu Tokai University, Japan

Dr. Jiangang Li, Institute of Plasma Physics, Chinese Academy of Sciences, People's Republic of China

Professor Yuping Huo, School of Physical Science and Technology, People's Republic of China

Library, Academia Sinica, Institute of Plasma Physics, People's Republic of China

Librarian, Institute of Physics, Chinese Academy of Sciences, People's Republic of China

Dr. S. Mirnov, TRINITI, Troitsk, Russian Federation, Russia

Dr. V.S. Strelkov, Kurchatov Institute, Russian Federation, Russia

Professor Peter Lukac, Katedra Fyziky Plazmy MFF UK, Mlynska dolina F-2, Komenskeho Univerzita, SK-842 15 Bratislava, Slovakia

Dr. G.S. Lee, Korea Basic Science Institute, South Korea

Institute for Plasma Research, University of Maryland, USA

Librarian, Fusion Energy Division, Oak Ridge National Laboratory, USA

Librarian, Institute of Fusion Studies, University of Texas, USA

Librarian, Magnetic Fusion Program, Lawrence Livermore National Laboratory, USA

Library, General Atomics, USA

Plasma Physics Group, Fusion Energy Research Program, University of California at San Diego, USA

Plasma Physics Library, Columbia University, USA

Alkesh Punjabi, Center for Fusion Research and Training, Hampton University, USA

Dr. W.M. Stacey, Fusion Research Center, Georgia Institute of Technology, USA

Dr. John Willis, U.S. Department of Energy, Office of Fusion Energy Sciences, USA

Mr. Paul H. Wright, Indianapolis, Indiana, USA 
The Princeton Plasma Physics Laboratory is operated by Princeton University under contract with the U.S. Department of Energy.

\author{
Information Services \\ Princeton Plasma Physics Laboratory \\ P.O. Box 451 \\ Princeton, NJ 08543
}

Phone: 609-243-2750

Fax: 609-243-2751

e-mail: pppl_info@pppl.gov

Internet Address: http://www.pppl.gov 